\title{
A violência contra idosos na mídia: uma reflexão sobre a produção dos sentidos
}

\begin{abstract}
RESUMO
No presente artigo se constrói uma reflexão acerca dos modos pelos quais um órgão da imprensa escrita, o Jornal da Paraíba (JP), da cidade de Campina Grande (Paraíba) tem noticiado situações de violência envolvendo indivíduos identificados como idosos. O estudo, abordando duas matérias recentes, pretende chamar a atenção para os ritos da construção da violência contra idosos como notícia. Quer-se pensar - e fazer pensar - acerca das implicações daquela textualização na construção de subjetividades governamentalizadas, endereçadas a corpos aprisionados pelos nomes da velhice.
\end{abstract}

\section{PALAVRAS-CHAVE}

Mídia

Violência

Velhice

\section{ABSTRACT}

The article reflects upon how the hard press named Jornal da Paraíba (JP), from Campina Grande (Paraíba), has reported violence against old people. The study, investigating two recent pieces of news reports, aims at calling attention to the construction of violence against old people as news report. It is necessary to think - and to make people think - about the implications of the way the governmentalized discourse is constructed, addressing imprisioned bodies by old age.

\section{KEYWORDS}

Media

Violence

Old age

\section{Alarcon Agra do Ó}

Professor do Programa de Pós-Graduação em História da UFCG/PB/BR velhice@gmail.com

\section{Rosângela Nascimento de Souza}

Graduanda em Ciências Sociais pela UFCG/PB/BR

velhice@gmail.com

\section{Thaiany da Costa}

Graduada em Ciências Sociais pela UFCG e em Comunicação Social pela UEPB/PB/BR

velhice@gmail.com

\section{Vanessa B. de Almeida}

Graduanda em História pela UFCG/PB/BR

velhice@gmail.com
Zygmunt Bauman (2009) tem chamado a atenção para a centralidade do medo e da busca por segurança no mundo contemporâneo. Suas palavras fazem um estranho eco à voz de Eric Hobsbawm (2007), para quem a violência é uma das experiências mais características e desastrosas da história do tempo presente. Para este último, padrões civilizatórios construídos com imensas dificuldades durante séculos pela sociedade ocidental teriam entrado em crise ao longo do século $X X$, em meio à eclosão de experiências variadas (e, muitas vezes, articuladas) de barbárie. Entre as formas de crise da civilização estariam as situações cada vez mais flagrantes de violência e de desrespeito aos direitos humanos por parte de Estados, de milícias armadas ou mesmo por indivíduos isolados.

Dados estatísticos oriundos de diversos lugares institucionais acabam por corroborar a percepção de Bauman e Hobsbawm. No presente, segundo a Organização Mundial de Saúde, ocorrem cerca de um milhão e meio de mortes violentas por ano em todo o mundo; na América Latina, de acordo com a Organização Panamericana de Saúde, ocorrem cerca de cento e vinte mil mortes violentas por ano (Briceño-León, 2005). Estudos como os realizados pela antropóloga Alba 
Zaluar têm indicado que o mesmo se dá, mais especificamente, em relação ao Brasil. O que diz aquela autora é que, no país, desde pelo menos os anos 1990, “o tema da violência [...] se tornou um dos que mais ocupa o debate público" (1998, p. 246), dada à degradação das relações sociais que temos experimentado e à disseminação da violência por incontáveis relações sociais. Pensando mais especialmente na dinâmica da violência em São Paulo, Teresa Caldeira (2000) aponta o quanto o cenário de proliferação do crime, com as suas consequentes experimentações de sofrimento e segregação, contribui para a fragilização da democracia no país.

\section{Ele parte de uma imagem justa do que deve ser a dinâmica social, e desde ali tece as imagens dos personagens daquela cena.}

A violência atinge a sociedade de forma disseminada, ainda que mereça ser pensada de forma a que sejam observadas as suas formas singulares (em relação às suas condições de possibilidade e aos seus impactos). Neste cenário, chama a atenção das ciências sociais e humanas a situação do homem e da mulher que são, no presente, aprisionados pelos nomes tantos da velhice (Barros, 1998; Lloret, 1998). Cada vez mais numerosos e mais visíveis no movimento de práticas históricas as mais diversas, os velhos e as velhas são personagens crescentemente envolvidos em situações de violência (Berquó, 2001, p. 20). Mais pontualmente, nos interessa estudar as formas pelas quais aquelas situações aparecem tematizadas na imprensa.

Ora, principalmente a partir dos anos 1990, tem havido na imprensa brasileira - mas não só nela - um maior empenho na divulgação de situações de violência envolvendo pessoas idosas. Raro é o mês em que não seja possível encontrar, nos jornais locais, alguma referência a situações nas quais uma ou mais pessoas nomeadas como idosas tenham sofrido alguma agressão. Os casos mais comuns são relacionados a danos patrimoniais, a conflitos familiares e a maus tratos em circunstâncias públicas (como nos ônibus, por exemplo), o que corresponde ao já indicado em estudos que se voltam para outras experiências sociais da mesma natureza (Berzins e Watanabe, 2005; Eckert, 2002; Minayo e Coimbra Jr., 2005).

O que explicaria isso, além do caráter violento da experiência histórica (brasileira) contemporânea, mencionado acima? Em relação aos crimes envolvendo idosos e à sua visibilidade na mídia, não pode ser negligenciada a profunda transformação demográfica sofrida pelo Brasil na atualidade, responsável pelo aumento da longevidade e do número de pessoas idosas. Há tanto mais velhos na sociedade quanto mais é alargada a expectativa de vida dos indivíduos. Aumentada a população de velhos, talvez cresça a possibilidade do acontecimento de situações de violência envolvendo os protagonistas daquela faixa de idade.

Tampouco se deve esquecer que, a partir dos anos 1990, tomou corpo no país um conjunto de instrumentos legais que emprestam outro sentido ao envelhecimento, na medida em que o indivíduo idoso passou a ser constituído, também, como portador de novos direitos. A configuração legal do sujeito velho o fez mais visível, inclusive no sentido de que situações que o envolvem acabam por ser vistas como experiências relacionadas mais ou menos diretamente à velhice.

Por fim, para mencionar algo que certamente atravessa os dois elementos mencionados anteriormente, difunde-se sem muitas dificuldades no presente a idéia de que falar da velhice atrai a atenção do público, cada vez mais desejoso de entender o seu próprio tempo na sua singularidade. A imprensa, enfim, quer falar do que chama a atenção do leitor (ainda que, como se saiba, a notícia crie, em muitos sentidos, o seu público consumidor).

No presente artigo se constrói uma reflexão acerca dos modos pelos quais um órgão da imprensa escrita, o Jornal da Paraíba, publicado na cidade de Campina Grande, mas com alcance em todo o Estado (e mais, se consideramos a sua edição on-line), tem noticiado situações de violência envolvendo indivíduos identificados como idosos. Quer-se chamar a atenção para os ritos da construção da violência contra idosos como notícia (Vivarta, 2003). Quer-se pensar - e fazer pensar - acerca das implicações daquela textualização na construção de subjetividades governamentalizadas, endereçadas a corpos aprisionados pelos nomes da velhice.

\section{Colocando o problema}

Para Arlette Farge (1993), o estudo histórico de práticas de violência tem um duplo papel. Por um lado, ele é pensado como a tentativa de se construir uma explicação sobre o que, especificamente, encena: situ- 
ações nas quais gestos que agridem se sobrepõem a quaisquer outros. Trata-se, nesse caso, aliás, de uma curiosidade antiga entre os historiadores, desde sempre afeitos a relatar guerras, revoluções, massacres indício talvez de alguma espécie de tensão permanente nos agrupamentos humanos, a qual se expressa belicosamente (Foucault, 1999, p. 285).

Por outro lado, num registro mais ampliado, diz Arlette Farge, estudar a violência é pensar e fazer pensar acerca dos modos pelos quais certa formação histórica elabora a si mesma em meio a asperezas. Ela chama a atenção para as possibilidades que se abrem, no instante em que se instala a oficina de uma historiografia da violência, para a problematização das formas pelas quais em cada sociedade, é delimitado o espaço propriamente dito "da violência". Ou seja: interessa pensar como são produzidos, historicamente, jogos de poder e saber que acabam por instituir o que é legítimo e o que não é, o que se pode e o que não se pode suportar, no tecido das relações sociais; dos efeitos que dali se produzem em relação à construção histórica das subjetividades e das sensibilidades. Em síntese, se "o funcionamento das sociedades também repousa sobre o conflito, a crise, a irrupção da violência dos corpos" (Farge, 1993, p. 768-769), a partir daí cabe ao historiador explorar os meandros do que emerge, desde ali, como o rosto de uma época.

Neste sentido, exploramos matérias jornalísticas do Jornal da Paraíba, nas quais se registrou/noticiou situações de violência envolvendo pessoas ali nomeadas como idosas. Buscamos entender a construção de sentidos para a experiência do envelhecimento, implicada na produção jornalística dedicada a registrar/relatar/encenar situações de violência envolvendo personagens daquela faixa etária.

Como Rita Garnel (2007), cremos que a pauta jornalística acerca de situações de violência é um indicativo razoável das preocupações recorrentes da opinião pública de sua época. O que se diz na mídia pode ser pensado, neste sentido, como uma discursividade que se relaciona de forma dinâmica com a sensibilidade que lhe é contemporânea, ao mesmo tempo se endereçando a um público cujo rosto imaginário é o de quem espera por aquele tipo de informação e contribuindo para forjar a receptividade àquele modo peculiar de relato. Quer-se crer, no âmbito do presente estudo, portanto, que o Jornal da Paraíba, ao relatar os casos a que nos referimos mira em dois alvos. Num sentido, ele busca corresponder ao que imagina ser a demanda do seu leitor; noutro, ele alimenta esta demanda, organizando-a nos termos de certa narratividade.
A matéria jornalística pode ser pensada, assim, como indicativa de uma agenda possível - desejável para o seu tempo e, especialmente, para os seus contemporâneos. Está implicada na lógica da notícia a descrição de experiências sociais na qual se insere de forma mais ou menos explícita uma hierarquização construída a partir de escalas de valores. Noticiar é, também, agenciar poder, e cada enunciação traz implicada em si a legitimação de condutas e o seu avesso. Na construção dos textos, como se verá a seguir, no exame de duas matérias do Jornal da Paraíba, coloca-se em cena uma espécie de pedagogia silenciosa. Aprende-se a ser velho com a leitura dos jornais, na medida em que o contato com experiências de violência pode ensinar condutas mais ou menos arriscadas, que não devem ser copiadas (Souza, s.d.).

\section{A nós interessa observar estes} momentos em que a dinâmica histórica se afualiza em práticas de linguagem, visto que nelas se constroem sentidos, os quais as atravessam e, de alguma forma, impregnam corpos, transformando-se em vida.

A mídia compõe imagens conflitantes para a velhice, construídas a partir da enunciação do risco inerente às práticas contemporâneas de sociabilidade. A vida social, dizem as mídias, é um território conflituoso por definição, e palco da vitimização inclemente dos mais frágeis, dos incautos, dos que não conseguem se impor pela força, pela vitalidade, pelo domínio dos códigos cada vez mais escorregadios e volúveis de um convívio individualizado e brutalizado (Bauman, 2009). Há, como se pode imaginar, uma produção desigual da subjetividade no discurso midiático. Ele parte de uma imagem justa do que deve ser a dinâmica social, e desde ali tece as imagens dos personagens daquela 
cena. Existem, então, os que nela se ajustam, e os que não - como transgressores ou como vítimas, estas últimas quase culpadas do que se lhes ocorreu, dada a sua incapacidade, voluntária ou não, de procurar o abrigo e a proteção que se instituem socialmente como corretos.

Como se pode compreender, a mídia é o palco no qual se encena uma textualização complexa da vida social - e da vida dos seus personagens - na qual se enredam, eventualmente, preconceitos, estereótipos, formas congeladas de se ver e dizer o mundo. Nela se atualiza o debate, caro à experiência histórica contemporânea, em meio ao qual toma corpo a idéia de que pensar e viver o presente só é possível a partir da consideração de que há vidas que não merecem a cidadania, ao passo em que há outras que quase se definem justamente pelo seqüestro de seu direito à existência legítima (Bauman, 2005). A nós interessa observar estes momentos em que a dinâmica histórica se atualiza em práticas de linguagem, visto que nelas se constroem sentidos, os quais as atravessam e, de alguma forma, impregnam corpos, transformando-se em vida.

O Jornal da Paraíba não faz, simplesmente, a transposição em palavras de uma cena do dia anterior: ele a refaz, a reelabora, emprestando-lhe um sentido que é tramado a partir do acionamento, na construção do texto, de uma política de verdade que é historicamente construída. A matéria jornalística ali tornada pública, assim, conta do seu tempo não apenas pelo que diz do que ocorreu, mas, ainda mais, pelas formas através das quais se organiza (Haroche, 1998).

É do governo dos velhos, e da velhice, portanto, que trata este estudo, nas suas questões de fundo (Gerzson, 2007). Procuramos, assim, mapear as formas pelas quais a mídia elabora e faz circular itinerários perigosos (logo, merecedores de prevenção) para os corpos envelhecidos. Vivemos num mundo cartografado pelo risco? E o risco, tornado espetáculo, ensina a viver? Dizer sim a estas duas perguntas é o nosso modo de afirmar uma hipótese de leitura e de pesquisa. Dela derivam nossas questões: o que diz a imprensa, quando trata de situações de violência envolvendo idosos? Quais os personagens daquelas histórias? Como eles são construídos? Qual a moral das histórias (o que se pode - ou deve - aprender ali?)? Como é tramado, ali, um modo correto de se viver? (Pelbart, 2003; Rose, 1988).

\section{0 estudo}

Dito tudo isso, cabe-nos observar que no dia dois de Janeiro de 2009 o Jornal da Paraíba trouxe a seguinte matéria:
Idoso é colocado em saco de lixo após ser espancado Por: RODRIGO APOLINÁRIO

O idoso Luiz Inocêncio, 63 anos, morador da Rua Nova, zona rural do município de Massaranduba, Agreste paraibano, foi assaltado, espancado e amarrado em um saco plástico, no início da noite da última quinta-feira, na Rua Santo Antônio, bairro de mesmo nome, em Campina Grande. Ele havia saído da fazenda onde trabalha, na zona rural de Campina Grande para comprar pão para os trabalhadores. Na volta, foi abordado por três homens.

Segundo ele, "os assaltantes queriam uma quantia em dinheiro que eu havia adquirido em uma viagem ao Rio de Janeiro, mas como não estava com o valor, acabei sendo espancado. Eles levaram os pães e o troco", destacou. Alguns assaltantes eram conhecidos da vítima. "Dois deles, eu conheço, pois trabalham comigo", apontou.

O idoso disse que só lembra que colocaram um saco plástico na sua cabeça. "Após ser espancado, só recordo que colocaram uma sacola na minha cabeça e quando acordei estava amarrado dentro de um grande saco de lixo", ressaltou.

Conforme a Polícia Militar, na manhã de ontem, quem o encontrou foi uma dona de casa residente na Rua Santo Antônio, que viu um saco após tocar com uma vassoura, percebeu que era um homem. Ela ligou para o Samu, que encaminhou a vítima para o Hospital Antônio Targino, onde, até o final desta edição ainda estava internado, em estado regular.

Temas recorrentes no debate contemporâneo sobre a velhice aparecem no texto acima: a legitimação do estatuto etário como demarcador inconteste da identidade; a situação de vulnerabilidade do idoso habitante da zona rural; a abjeção que parece impregnar a velhice, num tempo de intensa valorização da juventude.

O texto anuncia, desde seu título, a sua condição de matéria dedicada a tematizar uma experiência associada à velhice. $\mathrm{O}$ personagem mais importante da história contada, a vítima da situação de violência que se desejava relatar, é tratado de pronto como idoso. A sua idade, registrada ali como 63 anos, pesa-lhe, portanto como uma limitação identitária fundamental. Outra máscara não parece lhe corresponder, dado que o acúmulo de anos vividos o teria aprisionado num rosto do qual ele não conseguiria escapar.

No movimento de afirmação desta estereotipia se atualiza uma conduta ainda habitual na mídia: a identificação dos personagens das histórias contadas a partir de atributos que chamem a atenção do leitor, mesmo que necessariamente não contribuam para a explicação do havido. Ao indicar que algo se deu com um idoso, o Jornal não faz mais do que esboçar um liame 
entre a sua enunciação e a notável visibilidade obtida nos últimos anos por temáticas e questões relacionadas à velhice. Bombardeados insistentemente pela medicina, pelas ciências sociais e humanas e mesmo pela mídia, os leitores devem estar sensíveis a matérias que registrem eventos que envolvam pessoas velhas - parece pensar o jornal. O que se deu poderia ter ocorrido com pessoas de quaisquer faixas etárias, mas a enunciação de que a vítima é um idoso aciona certo arquivo de sentidos que interessa ao jornal dar visibilidade.

Principalmente, o JP aciona uma memória discursiva específica, das mais pregnantes na contemporaneidade: a que naturaliza a relação entre velhice e fragilidade. Abundam práticas culturais comprometidas com a afirmação desta verdade, desde matérias na imprensa, comerciais, cartilhas produzidas com ou sem apoio dos poderes públicos, obras artísticas etc. Vem se criando um consenso em torno da idéia de que o corpo envelhecido é frágil, o que se torna possível mediante a sua comparação com o corpo do indivíduo adulto jovem, tomado como o gabarito da corporalidade ideal.

É silenciada a historicidade desta associação, com o quê se esquece a sociedade presente que o movimento imagético que ela faz funcionar aí é algo humano, demasiado humano. E, mais, esquecemos, todos, que a avaliação do corpo velho através da sua comparação com um corpo jovem é a matriz de estereótipos e de hierarquizações nada favoráveis aos personagens da velhice. Ao contrário, a eleição de certos atributos corporais e a sua associação à força e à beleza que são, também, tomadas acriticamente como padrões legítimos para a existência humana, é um gesto que traz consigo a estigmatização de indivíduos, de trajetórias, de escolhas de vida.

Interessou ainda ao JP informar que o dito idoso é morador de uma rua situada na Zona Rural de Massaranduba, um município no qual a Zona Urbana é quase inexistente, sendo funcionário de uma fazenda. Além disso, o crime se deu em uma rua que, sendo extensa, atravessa um bairro de Campina Grande e se encontra ao seu final com o início da vizinha Massaranduba, permitindo o contato entre áreas ruralizadas de ambos os municípios. Com isso há o apelo a uma espécie de repertório imagético que tem se legitimado recentemente na região polarizada por Campina Grande, o qual dá conta do aumento dos casos de violência contra idosos pelas cercanias das cidades, nas regiões menos urbanizadas e mais distantes do policiamento ostensivo.
Esta tem sido uma verdade recorrente nos últimos anos, na imprensa paraibana: os idosos que habitam o campo, distribuídos em propriedades que normalmente se localizam distantes umas das outras e em geral morando sozinhos ou na companhia de poucos parentes, são vítimas preferenciais de criminosos. Morar longe da cidade tornaria aqueles indivíduos pessoas talvez pouco afeitas aos códigos de sociabilidade do mundo urbano, no qual a maior presença de situações de violência acaba por tornar a (quase) todos excessivamente vigilantes em relação ao outro. Mais uma vez funciona aqui uma maquinaria de comparações que enfraquece a experiência do indivíduo envelhecido visto como menos preparado para a vida que o homem urbano. Além disso, por serem conhecidos na região por beneficiários de algum provento mensal, os idosos, reitera o JP com grande regularidade, são atacados frequentemente com violência. Confiantes na baixa capacidade de reação de suas vítimas, bem como na dificuldade de acesso da polícia a certas áreas remotas, os bandidos agem quase impunemente, deixando atrás de si um rastro de perdas materiais, de corpos agredidos, eventualmente de cadáveres.

\section{No movimento de afirmação desta estereotipia se atualiza uma conduta ainda habitual na mídia: a identificação dos personagens das histórias contadas a partir de atributos que chamem a atenção do leitor, mesmo que necessariamente não contribuam para a explicação do havido.}

Mas, considerando o texto que se analisa aqui, talvez o que mais surpreenda o leitor - ou o incomode é o que foi sintetizado no título mesmo da matéria. $\mathrm{O}$ idoso que sofreu a violência, de acordo com a matéria 
do $J P$, foi objeto de três situações de violação de seus direitos. Num primeiro nível, ele foi "abordado por três homens" que queriam subtrair-lhe certa quantia; num segundo nível, ali está dito que ele foi "espancado" pelos assaltantes, provavelmente irritados porque sua vítima portava apenas pouco dinheiro; por fim, num terceiro e mais dramático lance da história, o idoso foi "colocado num saco de lixo e deixado na via pública".

Os criminosos, apesar de conhecidos da vítima, não relutaram em praticar aquela série de gestos violentos, culminando com a conversão do idoso em lixo. A felicidade daquele indivíduo foi o pacote em que estava amarrado ter sido mexido por uma dona de casa a qual, segundo o $J P$, numa sentença carregada quase de força poética, "percebeu que era um homem". Um homem: um ser dotado, segundo as leis e os costumes do lugar, de direito à dignidade e ao respeito, e que vira nas horas anteriores à sua retirada do lixo a sua degradação mais abissal. Ele havia sido violado no seu patrimônio, no seu direito de ir e vir, na sua corporalidade, na sua condição de pessoa - a cena do crime sendo assim o palco da sua animalização (da coisificação).

Os assaltantes construíram, com os seus gestos, sem querer, uma grande peça dramática. Eles condensaram no seu procedimento, é o que se pode refletir pela leitura da matéria do $J P$, todo um conjunto de estratégias comprometidas com a produção da velhice como a experiência abjeta por definição no mundo contemporâneo. Assaltar, espancar e, por fim, ensacar o corpo agredido, igualando-o ao lixo de todos os dias, ao refugo banal das práticas cotidianas mais irrefletidas - ali parece estar condensada uma forma de se pensar e de se viver o envelhecimento que não deveria ser deixada de lado, sem uma reflexão séria. Como se torna possível, mesmo em situações-limite, o gesto de se jogar uma pessoa no lixo? E o que resulta de sua transformação em notícia?

No dia oito de Janeiro de 2009, mais uma matéria ocupou a página policial do Jornal da Paraíba:

\section{Bandidos matam idoso de $\mathbf{7 7}$ anos a pauladas Por: DA REDAÇÃO}

Uma morte com requintes de crueldade revoltou e deixou chocados os moradores do Sítio Meia Patada, zona rural do município de Remígio, no Agreste paraibano. O aposentado Rubens Barbosa da Silva, de 77 anos, foi assassinado com várias pauladas e espancado na noite da última segunda-feira. Segundo a polícia, o crime teria sido provocado por bandidos não identificados que invadiram a casa da vítima durante um assalto.

O corpo do agricultor só foi encontrado na manhã de ontem pela polícia, sentado em uma cadeira na cozinha da residência onde ele morava sozinho, porque os moradores do sítio não conseguiram entrar em contato com os policiais na noite do crime. Segundo os policiais, a casa do aposentado foi completamente revirada pelos bandidos, que possivelmente estavam à procura do dinheiro da aposentadoria da vítima.

Depois de cometerem o latrocínio, os criminosos ainda tentaram enterrar o corpo do aposentado, e cavaram dois buracos próximos ao local do crime, mas acabaram desistindo da ação. Ainda de acordo com a polícia da cidade de Remígio, o crime ainda está sendo investigado, mas outra hipótese que está sendo apontada é o envolvimento de um esposo de uma amante da vítima no caso.

Antes de executarem Rubens Barbosa, os bandidos podem ter também violentado sexualmente a vítima, já que ele foi encontrado sem roupa pela polícia. "Foi um ato de barbárie. Casos como esse estão acontecendo aqui em Remígio, e possuem como vítimas aposentados que moram na zona rural", disse o agente Gadelha, da Polícia Civil, que trabalha na cidade. O corpo do aposentado foi encaminhado para a Unidade de Medicina Legal de Campina Grande, para ser necropsiado.

No final da manhã de ontem, a polícia conseguiu prender três pessoas suspeitas de participação no crime, que não tiveram os nomes divulgados pelos policiais porque ainda iam ser ouvidas. Uma quantia em dinheiro não divulgada pela família também foi levada do aposentado. Para os familiares, não havia nenhum motivo para o crime.

No tratamento do crime acima relatado, o JP aciona, como no caso que foi mencionado anteriormente, a idade como fator de identificação dos personagens da história contada. Alia a isso a condição de "aposentado", forma comum de fazer referência à idade dos personagens das matérias, numa associação entre a velhice e o não-trabalho.

Uma tensão atravessa o texto, mesmo não tendo sido explicitada na sua manchete. Trata-se de algo que não foi deixado de lado pela "Redação" (autoria anônima que esconde articulações nem sempre tranqüilas no cotidiano de um órgão de imprensa): a dimensão sexual do crime. Tudo é trazido à primeira cena sob a forma de hipóteses; repercutindo a lógica enunciativa própria do jargão policial e jurídico, o $J P$, naquela matéria, menciona duas questões que implicam na discussão quanto à experiência da sexualidade pela vítima.

Em primeiro lugar, a hipótese do latrocínio é colocada em questão, visto que uma condição peculiar do idoso assassinado o tornaria potencialmente vulnerável a uma agressão de outra natureza. Não que aquela não fosse uma hipótese plausível: o JP trabalha com a 
idéia, já parte integrante da memória coletiva campinense em relação ao seu presente mais próximo, de que os indivíduos idosos são mais vulneráveis a latrocínios, dada à combinação entre sua condição quase universal de beneficiários de rendimentos previdenciários e sua fragilidade física. Aquele senhor que ali se transformara tristemente em notícia, por outro lado, estaria envolvido com uma mulher casada, sendo seu amante. O marido traído, sabedor do adultério, talvez desejasse vingar-se, a morte do seu concorrente sendo a saída mais legítima para tanto. Brota daí uma hipótese tão forte que concorre com a do latrocínio.

Em segundo lugar, há a menção a uma suposta violência sexual que pode ter sido praticada contra o idoso, cujo corpo foi encontrado despido. Por que desnudar um corpo, a não ser para abusar dele? Que abuso seria mais radical do que aquele que inverteria a sexualidade manifesta, o que se daria mediante uma violação, uma penetração forçada? Aquela violência talvez se ligasse, é o que o JP acaba por deixar implícito, a uma tensão característica das formas pelas quais se vive (e em nome da qual se morre) a masculinidade no Nordeste brasileiro. Um homem local - masculinizado à última potência - não hesitaria em violar o corpo de quem fosse suspeito de estar maculando a honra de sua companheira, o sagrado leito conjugal, a dignidade de quem é traído.

Chama a atenção, por fim, a última informação da matéria: "Para os familiares, não havia nenhum motivo para o crime." O que motivaria, para aquela família, um crime? Por que os familiares se preocuparam em confirmar a desaparição de algum valor monetário? Eles viam nisso a possibilidade de fazer esquecer a possível violação sexual do parente morto - ela própria uma vergonha que se abateria por sobre o falecido e, por aproximação, numa herança indesejada, para a sua parentela? Mas o que poderia ter ocorrido que justificasse uma agressão, uma violação dos direitos humanos, uma violência? O que o JP quer dizer quando dá visibilidade à idéia de situações como aquelas, talvez, pudessem ser explicadas - ou legitimadas - na eventualidade de sua inserção numa série outra de eventos? O que está implícito, ali?

\section{Palavras finais}

A pesquisa que permitiu este artigo não tem o objetivo de registrar as práticas de violência que vitimizam pessoas idosas na região polarizada por Campina Grande. Ainda que um esforço daquela natureza tenha a sua importância, o que se tem realizado por nossa equipe tem sido, isto sim, o mapeamento dos modos pelos quais aquelas situações são representadas na imprensa, especialmente, no Jornal da Paraíba.

$\mathrm{O}$ dissenso entre perspectivas quantitativas e qualitativas de pesquisa no âmbito das ciências sociais e humanas não nos seduz, entretanto; antes, ele nos parece uma postura equivocada - implicada, como talvez dissesse Michel Foucault, na produção de efeitos de opinião ao invés de efeitos de verdade. Assim, não julgamos inválidos estudos que se dediquem a examinar com as armas da quantificação a violência que se espraia por sobre os corpos envelhecidos ao nosso redor. O que se dá, entretanto, é que a nossa escolha tem sido a de executar um mergulho o mais profundo possível (temos os nossos limites, é óbvio) em textos publicados no $J P$, em busca de uma compreensão quanto aos modos pelos quais ali se produz sentido.

\section{JP aciona uma memória discursiva específica, das mais pregnantes na} contemporaneidade: a que naturaliza a relaçáo entre velhice e fragilidade.

Como a leitura do artigo deve indicar, pratica-se uma abordagem histórico-discursiva, a qual se estabelece como um esforço de emprestar densidade temporal a fatos do discurso. E o que temos percebido é a pregnância, no discurso jornalístico, de certa sensibilidade social em torno do envelhecimento humano. Tal sensibilidade é tecida com uma mescla heterogênea de fios, alguns marcados pelas cores dos estereótipos, outros pelos tons do reconhecimento dos direitos humanos da pessoa idosa, outros mais pelas sombras de uma sociabilidade vincada pela dureza e pela inclemência da barbárie.

O Jornal da Paraíba, do ponto de vista da nossa análise, não está certo ou errado: ele, apenas, sintetiza nas suas páginas os dramas e as tramas da sua própria historicidade. Neste sentido, suas enunciações são de interesse para as ciências humanas e sociais, visto que nelas se condensam imagens socialmente construídas, práticas que falam de si e do seu mundo.

O Jornal da Paraíba, nas matérias que explorarmos aqui, nos fala, a partir de suas escolhas, de uma velhi- 
ce que se atualiza como presença histórica a partir de uma fragilidade fundamental - em meio à qual tudo se torna porta de entrada para o perigo, até mesmo o benefício de uma renda mensal, ou o de uma habitação própria, ou o da autonomia ainda experimentada na gestão do corpo e da vida.

\section{0 que temos percebido é a}

\section{pregnância, no discurso}

\section{jornalístico, de certa sensibilidade}

\section{social em torno do}

envelhecimento humano. Tal

sensibilidade é tecida com uma

mescla heterogênea de fios,

alguns marcados pelas cores dos

estereótipos, outros pelos tons do

reconhecimento dos direitos

humanos da pessoa idosa, outros

mais pelas sombras de uma

sociabilidade vincada pela dureza

e pela inclemência da barbárie.

Além disso, as duas matérias lidas acima nos falam, nas suas entrelinhas, de uma moralidade idealizada para o indivíduo envelhecido. Para não se arriscar tanto, parece dizer em silêncio cada matéria, o idoso deveria abrir mão de ser quem ainda é, e esconder os ganhos, mudar-se para ruas movimentadas, agregar-se quem sabe em casas de parentes, silenciar o desejo sexual, apagar-se na paisagem, dissolver-se, esfumar-se. O tempo presente, ao menos para os idosos pobres e habitantes do campo, não é acolhedor a quem não é jovem, forte, ágil. Por que não simular isso? Por que não isolar-se disso?

Instala-se, ali, um não lugar para a velhice, aliás, já apontado em outro contexto por Norbert Elias (2001). Numa época em que as relações entre povos e pessoas se dão gabaritadas pela violência, as vítimas potenciais mais visíveis devem sucumbir ou desaparecer (Agra Do Ó, 2008). Tende a sumir aquilo que Bauman aponta como o elemento definidor da espécie humana, ou seja, o cuidado mútuo entre os indivíduos, a relação de identificação de uns em relação aos outros que torna a todos cúmplices de um mesmo projeto - que é o da sobrevivência com dignidade (2009, p. 90).

A Imprensa atua neste cenário representando, apresentando, presentando cenas que remetem a outras cenas, atualizando histórias que se enredam em outras histórias. O resultado do seu gesto, mesmo sendo algo precário e humano, demasiado humano, é a produção de sentidos. Sentidos com os quais os leitores passam a contar para a sua permanente (re)invenção de si, ou seja, para aquilo que chamamos de vida, de experiência social, de trajetória a faMEcos

\section{REFERÊNCIAS}

AGRA DO Ó, Alarcon. Norbert Elias e uma narrativa acerca do envelhecimento e da morte. História, Ciências, Saúde. Manguinhos [online]. 2008, vol.15, n.2, p. 389400.

BARROS, Myriam Moraes Lins de. (org.) Velhice ou terceira idade? Estudos antropológicos sobre identidade, memória e política. Rio de Janeiro: Editora Fundação Getúlio Vargas, 1998.

BAUMAN, Zygmunt. Vidas desperdiçadas. Rio de Janeiro: Jorge Zahar Editor, 2005.

BAUMAN, Zygmunt. Confiança e medo na cidade. Rio de Janeiro: Jorge Zahar Editor, 2009.

BERQUÓ, Elza. Evolução demográfica. In: SACHS, Ignacy. et alli. (Orgs). Brasil: um século de transformações. São Paulo: Companhia das Letras, 2001.

BERZINS, Marília Anselmo Viana da Silva e WATANABE, Helena Akemi Wada. Violência contra idosos: do invisível ao visível? In: CORTE, Beltrina. et. alii. (orgs.) Velhice, envelhecimento, complex(idade). São Paulo: Vetor, 2005.

BRICEÑO-LEÓN, Roberto. Violencia interpersonal: salu publica y governabilidad. In: MINAYO, Maria Cecília de Souza \& COIMBRA JR., Carlos E. A. (orgs.) Críticas e atuantes. Ciências sociais e humanas em saúde na América Latina. Rio de Janeiro: Editora FIOCRUZ, 2005. 
CALDEIRA, Teresa Pires do Rio. Cidade de muros. Crime, segregação e cidadania em São Paulo. São Paulo: Ed. 34 / EDUSP, 2000.

CORTE, Beltrina e GOMES, Mayra Rodrigues. Velhice e violência: o outro lado das notícias e cobertura. In: XXX Congresso Brasileiro de Ciências da Comunicação, 2007.

ECKERT, Cornelia. A cultura do medo e as tensões do viver a cidade: narrativa e trajetória de velhos moradores de Porto Alegre. In: MINAYO, Maria Cecília de Souza e COIMBRA JR., Carlos E. A. (Orgs.) Antropologia, saúde e envelhecimento. Rio de Janeiro: Editora FIOCRUZ, 2002.

ELIAS, Norbert. A solidão dos moribundos. Seguido de "Envelhecer e morrer". Rio de Janeiro: Jorge Zahar. 2001.

FARGE, Arlette. Violência. In: BURGUIÈRE, André. (Org.) Dicionário das ciências históricas. Rio de Janeiro: Imago, 1993.

FOUCAULT, Michel. Em defesa da sociedade. São Paulo: Martins Fontes, 1999.

GARNEL, Maria Rita Lino. Vítimas e violências na Lisboa da I República. Coimbra: Imprensa da Universidade de Coimbra, 2007.

GERZSON, Vera Regina Serezer. A mídia como dispositivo da governamentalidade neoliberal - os discursos sobre educação nas revistas Veja, Época e Isto é. Tese de Doutorado. Porto Alegre: Universidade Federal do Rio Grande do Sul; Programa de Pós-Graduação em Educação, 2007.
HAROCHE, Claudine. Da palavra ao gesto. Campinas: Papirus, 1998.

HOBSBAWM, Eric. Globalização, democracia e terrorismo. São Paulo: Companhia das Letras, 2007.

LLORET, Caterina. As outras idades ou as idades do outro. In: LARROSA, Jorge e LARA, Nuria Pérez de. (Orgs.) Imagens do outro. Petrópolis: Vozes, 1998.

MINAYO, Maria Cecília de Souza e COIMBRA JR., Carlos E. A. (Orgs.) Críticas e atuantes. Ciências sociais e humanas em saúde na América Latina. Rio de Janeiro: Editora FIOCRUZ, 2005.

PELBART, Peter Pál. Biopolítica. In: PELBART, Peter Pál. Vida capital. Ensaios de biopolítica. São Paulo: Iluminuras, 2003.

ROSE, Nikolas. Governando a alma: a formação do eu privado. In: SILVA, Tomaz Tadeu da. (Org.) Liberdades reguladas. A pedagogia construtivista e outras formas de governo do eu. Petrópolis: Vozes, 1998.

SOUZA, Pedro de. Dentro e fora: violência e irrupção urbana em cidades médias. In: Escritos. Publicação do Laboratório de Estudos Urbanos - LABEURB - NUDECRI - UNICAMP, s.d.

VIVARTA, Veet. O grito dos inocentes. Os meios de comunicação e a violência sexual contra crianças e adolescentes. São Paulo: Cortez, 2003.

ZALUAR, Alba. Para não dizer que não falei de samba: os enigmas da violência no Brasil. In: SCHWARCZ, Lilia Moritz. História da vida privada no Brasil. Contrastes da intimidade contemporânea. São Paulo: Companhia das Letras, 1998. 